\title{
Factors affecting emotional eating and eating palatable food in adults
}

\author{
Saniye Bilici, Busra Ayhan§, Efsun Karabudak and Eda Koksal \\ Department of Nutrition and Dietetics, Faculty of Health Sciences, Gazi University, Besevler, Ankara, 06500 Turkey
}

BACKGROUND/OBJECTIVES: The aim of this study was to determine the relationship among emotional eating behavior, tendency to eat palatable foods, and several risk factors.

SUBJECTS/METHODS: This study was carried out on 2,434 persons (1,736 women and 698 men) aged between 19 and 64 years. A questionnaire form was used as a data collection tool, which consisted of items for the socio-demographic characteristics, anthropometric measurements, Emotional Appetite Questionnaire (EMAQ), and the Palatable Eating Motives Scale (PEMS). RESULTS: A positive significant correlation was observed between the BMl groups and the negative emotions, negative situations, and negative total scores of EMAQ $(P<0.01)$. The regression results on negative subscales showed that a one unit increase in BMl resulted in a 0.293 unit increase in negative situations scores, a 0.626 unit increase in negative emotions scores, and a 0.919 unit increase in negative total EMAQ scores. When the BMl groups and PEMS subscale scores were examined, a significant relationship was found in the social motives, rewarding, and conformity subscales $(P<0.01)$. A one unit increase in BMl increased the coping motives scores by 0.077 units.

CONCLUSION: The emotional states have a significant effect on the eating behavior. On the other hand, an increase in eating attacks was observed, particularly in people who were under the effect of a negative emotion or situation. Nevertheless, there were some limitations of the study in terms of quantitative determination of the effects of this eating behavior depending on the BMI.

Nutrition Research and Practice 2020;14(1):70-75; https://doi.org/10.4162/nrp.2020.14.1.70; pISSN 1976-1457 elSSN 2005-6168

Keywords: EMAQ, PEMS, emotional eating, BMI, palatable food, motivation eating

\section{INTRODUCTION}

It is known that negative emotions or stress in the body can cause a symptom similar to the sense of postprandial satiety, resulting in the lack of appetite or decreased nutritional intake. In some cases; however, an opposite reaction of increased eating can be seen [1].

Eating behavior in order to cope with negative emotions is called "emotional eating" [2]. Individuals, with emotional eating behavior, eat for motives other than hunger. These individuals generally continue to eat while the balance of homeostatic energy change to positive direction, especially in the face of emotional situations. It is stated that such eating behavior may result in obesity [3]. There are several different theories on the mechanism that why the obese individuals particularly have more emotional eating behavior than the normal weighted ones. According to psychosomatic theory, perception of satiety or hunger is weaker in the obese and this leads to a constant eating behavior under the slightest stimulation [3]. According to externality theory, contractions in the stomach caused by fear or nervousness or in the case of stress cause a decrease in nutrient intake in normal weight individuals. However, obese individuals develop the opposite reaction in these situations.
They are extremely sensitive to any stimuli they may experience related to foods, but not sensitive enough to physiological stimulants of hunger and satiety [4]. According to containment theory, external nutritional stimulants or negative emotions inhibit the restriction of hyperphagia and weight gain in obese [5]. In escape theory, when the individuals feel that they are confronted with any stimuli that threatens themselves, they also develop a defense mechanism by giving their attention to more distinct external stimuli such as excessive eating behavior [6].

Changes in eating behavior due to fluctuations in their emotional state can also be caused by situations or events out of the daily routine of a person, such as adapting to certain environments, motivating oneself, rewarding or coping with any situation [7]. It is stated that the eating changes experienced in these cases are generally directed towards increasing the intake of palatable foods such as delicious foods, fast foods, sugary products or snacks. It is emphasized that the consumption of such foods takes the place of regular meals and they may enter the normal diet of individuals [8-10]. This style eating is more common in female than male in Turkey [11]. Considering foods with high fat and sugar content trigger excessive eating, being overweight or obesity as a result of this type of eating behavior is inevitable [12].

\footnotetext{
${ }^{\S}$ Corresponding Author: Busra Ayhan, Tel. 90-312-216-50-17, Fax. 90-312-216-26-36, Email: busraayhan989@gmail.com

Received: May 15, 2019, Revised: June 5, 2019, Accepted: July 9, 2019

This is an Open Access article distributed under the terms of the Creative Commons Attribution Non-Commercial License (http://creativecommons.org/licenses/by-nc/3.0/) which permits unrestricted non-commercial use, distribution, and reproduction in any medium, provided the original work is properly cited.
} 
Both emotional eating behavior and the increase in the intake of palatable foods are seen as two risk factors that may increase the risk of obesity in society. In our country, there are studies about eating behavior disorder and obesity. However, the study of emotional eating and palatable foods associated with BMI is very limited. This type of studies, especially in adults, are very rare in Turkey [13]. The aim of this study was to determine the relationship between emotional eating behavior, tendency to eat palatable foods and several risk factors.

\section{SUBJECTS AND METHODS}

\section{Subjects}

This study was carried out in Ankara and Nevsehir, the cities located in the Central Anatolia region of Turkey. A totally 2,434 persons (1,736 women and 698 men) between the ages of 19-64 participated in the study. The number of the selected sample has been extended to represent the general population and $0.5 \%$ of the whole sample was included in the study. Pregnant and lactating women, individuals with a diagnosed psychiatric condition that affected their emotional state, and those with eating disorders were not included in the study.

\section{Ethical issues}

This study approved by the ethics committee of Gazi University on December 07, 2016 (Document No: 77082166-604.01.02.).

\section{Study design}

Questionnaire form was used as data collection tool in the study by face-to-face interviews. The questionnaire consists of items about, gender, date of birth, education level, duration of education, working status, occupation, and marital status of participants and also Emotional Appetite Scale and the Palatable Eating Motives Scale were used. Also, the body weight and height were measured by trained researchers and body mass index (BMI) was obtained by dividing body weight $(\mathrm{kg})$ by height squared $\left(\mathrm{m}^{2}\right)$. BMl classification was made according to the WHO (World Health Organization) classification. (BMI < 18.5: underweight, BMI 18.5-24.9: normal, BMI 25.0-29.9: overweight, BMI $\geq 30.0$ : obese).

\section{The emotional appetite questionnaire - EMAQ}

Emotional Appetite Scale was developed by Nolan et al. [5] and the Turkish validity and reliability study was performed by Demirel et al. [2]. The scale is aimed at evaluating emotional eating, and participants score each statement in terms of how much certain emotions and negative and positive situations affects their appetite (less (1-4), same (5), and more (6-9). The presence of emotional eating is assessed by negative/positive emotions (14 items) and negative/positive situations (8 items). The total score of negative emotions $(1,2,4,5,7,8,9,10$, 13) and negative situations $(15,16,17,19,21)$ gives the total Negative EMAQ score, whereas the total score of positive emotions $(3,6,11,12,14)$ and positive situations $(18,20,22)$ gives the total positive EMAQ score. There is no cut off point in the scale related to emotional eating, and it assesses emotions and situations in which emotional eating may occur. Cronbach's alpha coefficients of the subscales were; 0.771 for negative emotions, 0.781 for negative situations, 0.852 for positive emotions, and 0.574 for positive situations. The total Cronbach's alpha coefficients of the EMAQ was found 0.882 .

\section{Palatable eating motives scale - PEMS}

PEMS is a 5 likert-type questionnaire consisting of 20 items that measures motives for eating a variety of palatable foods and beverages. It includes subscales of social, coping, reward enhancement, and conformity motives. Social motives include questions about consuming palatable foods or beverages for social reasons (e.g. consumption to enjoy a party, eating behavior shown to socialize more with friends, etc.). Social motive score is obtained by the sum of questions $3,5,11,14,16$ that include these items. Coping motive includes items related to the consumption of palatable foods or beverages to deal with negative feelings (such as anxiety, eating behavior in a sad situation, depression, or eating behavior related to frustration and anger). Coping motive score is obtained by the sum of questions 1, 4, 6, 15, 17 that include these items. Reward enhancement motive involves questions about consuming palatable foods or drinks to enhance positive experiences, emotions or inherent satisfying traits that are not related to social situations (for example: eating behavior towards foods that give pleasure, or make the individual happy when consumed). Enhancement score is obtained by the sum of questions 7, 9, $10,13,18$ containing these items. Conformity motive involves questions about consumption of palatable foods in response to external pressures (e.g. conformity to social environments with friends, eating behavior shown to avoid being excluded). Conformity motive score is obtained by the sum of questions $2,8,12,19,20$ that contain these items [14]. The scale was translated from English into Turkish and adapted with palatable foods liked by Turkish population [15]. Cronbach's alpha coefficients of the subscales were; 0.874 for social motives, 0.860 for coping motives, 0.871 for reward enhancement, and 0.804 for conformity. The total Cronbach's alpha coefficients of PEMS was found 0.937 .

\section{Statistical analysis}

Statistical analysis was performed using SPSS version 15.0 software. ANOWA was used to determine differences in subscale scores between males and females and between BMI groups. Relationships between the subscales of EMAQ and PEMS scales were examined by Pearson correlation tests. Independent effects on BMI between EMAQ and PEMS subscale scores were examined by a multivariate linear regression model. Statistical significance was assessed according to 95\% and 99\% significance levels.

\section{RESULTS}

\section{Participants characteristics}

The $28.7 \%$ of the 2,434 participants in the study were male and $71.3 \%$ were female. Mean age of the participants was 26.1 \pm 8.80 years and mean BMl was $23.1 \pm 4.33 \mathrm{~kg} / \mathrm{m}^{2}$ (male: 24.90 $\pm 3.82 \mathrm{~kg} / \mathrm{m}^{2}$, female: $22.42 \pm 4.32 \mathrm{~kg} / \mathrm{m}^{2}$ ). $7.4 \%$ of the participants were underweight, $65.9 \%$ were normal, $20.2 \%$ were overweight and $6.5 \%$ were obese. 
Table 1. Distribution of EMAQ and PEMS subscale scores according to gender

\begin{tabular}{lcccc}
\hline & $\begin{array}{c}\text { Male } \\
(n=698) \\
\text { Mean } \pm \text { SD }\end{array}$ & $\begin{array}{c}\text { Female } \\
(\mathrm{n}=1,736) \\
\text { Mean } \pm \text { SD }\end{array}$ & $t$ & $P$ \\
\hline EMAQ & & & & \\
$\quad$ Negative emotion & $37.19 \pm 15.06$ & $37.10 \pm 14.31$ & 0.13 & 0.89 \\
Negative situation & $18.59 \pm 9.91$ & $17.28 \pm 9.45$ & 3.05 & $0.00^{* *}$ \\
Total negative score & $55.78 \pm 23.42$ & $54.38 \pm 21.50$ & 1.41 & 0.15 \\
Positive emotion & $27.24 \pm 8.20$ & $26.89 \pm 7.52$ & 1.00 & 0.31 \\
Positive situation & $15.31 \pm 5.44$ & $14.89 \pm 5.59$ & 1.74 & 0.08 \\
Total positive score & $42.56 \pm 12.51$ & $41.78 \pm 11.41$ & 1.47 & 0.14 \\
PEMS & & & & \\
Social & $11.60 \pm 5.54$ & $12.11 \pm 5.07$ & -2.10 & $0.03^{*}$ \\
Coping & $8.03 \pm 4.78$ & $9.46 \pm 4.95$ & -6.48 & $0.00^{* *}$ \\
Reward enhancement & $10.23 \pm 5.13$ & $11.33 \pm 5.31$ & -4.66 & $0.00^{* *}$ \\
Conformity & $6.74 \pm 3.96$ & $6.41 \pm 3.63$ & 1.92 & 0.54 \\
\hline * P<0.05, ** $P<0.001$ & & & &
\end{tabular}

EMAQ and PEMS subscale scores by gender

When EMAQ and PEMS subscale scores were examined according to gender, a significant difference was found between males and females only in the negative situations subscale of EMAQ $(P<0.05)$, and the mean score of males in the negative situations subscale of EMAQ was found to be significantly higher. In PEMS, a significant difference in socialization, coping and rewarding subscales was found between genders $(P<0.05)$. Women's scores in these subscales were significantly higher than men's. No significant difference was found in the conformity subscale of PEMS between genders $(P>0.05)$ (Table 1$)$.

\section{EMAQ and PEMS subscale scores by BMI}

There was a positive significant correlation between BMI groups and the negative emotions, negative situations, and negative total scores of EMAQ $(P<0.01)$. Accordingly, it was determined that the total negative EMAQ scores of underweight participants were lower than other BMI groups $(P<0.05)$. It was found that total negative EMAQ scores of participants with normal BMI were significantly lower than those of overweight and obese participants $(P<0.05)$. However, there was no correlation between BMl groups and positive emotions, positive situations and positive total scores of EMAQ (Table 2).

When a negative relationship was found between $\mathrm{BMI}$ and social, reward, and conformity subscale score $(P<0.01)$, whereas no relation was found in coping subscale. It was determined that the average social motives score of participants with underweight and normal BMI in the socialization subscale was significantly higher than that of mildly obese and obese people. In the rewarding subscale, it was seen that underweight participants received higher scores than mildly obese participants $(P<0.05)$. It was also seen that participants with normal BMI received higher scores in the rewarding subscale compared to mildly obese and obese participants $(P<0.05)$. It was found that conformity subscale scores of participants with normal BMl were higher than mildly obese participants $(P<0.05)$ (Table 2$)$.

Table 2. Distribution of EMAQ and PEMS subscale scores according to BMl groups

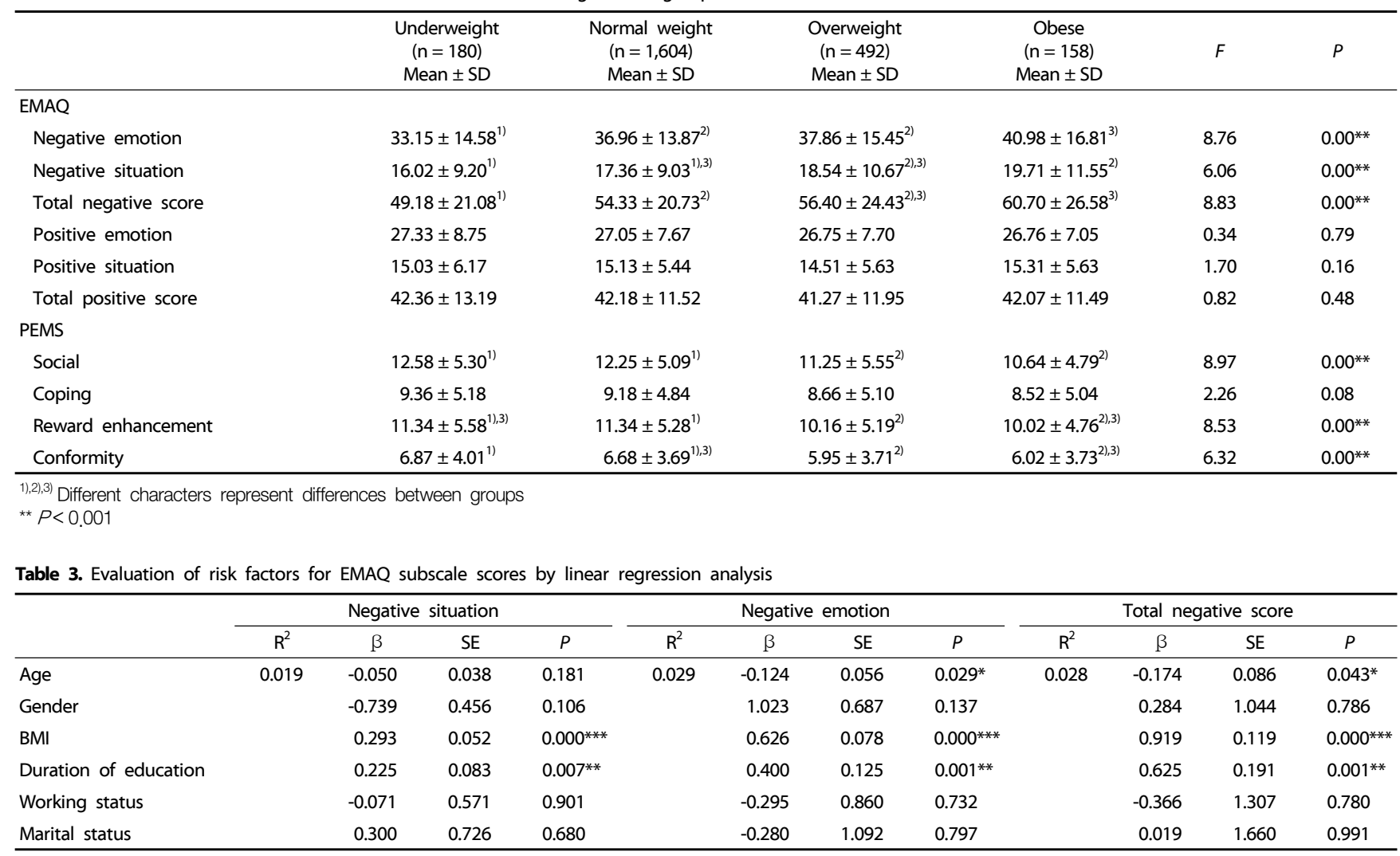

${ }^{\star} P<0.05,{ }^{* \star} P<0.001,{ }^{* \star \star} P<0.0001$ 
Table 4. Evaluation of risk factors for PEMS subscale scores by linear regression analysis

\begin{tabular}{|c|c|c|c|c|c|c|c|c|c|c|c|c|c|c|c|c|}
\hline & \multicolumn{4}{|c|}{ Social } & \multicolumn{4}{|c|}{ Coping } & \multicolumn{4}{|c|}{ Reward enhancement } & \multicolumn{4}{|c|}{ Conformity } \\
\hline & $\mathrm{R}^{2}$ & $\beta$ & SE & $P$ & $\mathrm{R}^{2}$ & $\beta$ & SE & $P$ & $\mathrm{R}^{2}$ & $\beta$ & SE & $P$ & $\mathrm{R}^{2}$ & $\beta$ & SE & $P$ \\
\hline Age & 0.032 & -0.053 & 0.020 & $0.009^{* *}$ & 0.046 & -0.060 & 0.019 & $0.002^{* *}$ & 0.039 & -0.054 & 0.020 & $0.009^{* *}$ & 0.029 & -0.029 & 0.015 & $0.044^{*}$ \\
\hline Gender $^{1)}$ & & 0.089 & 0.246 & 0.718 & & 1.187 & 0.232 & $0.000^{* * *}$ & & 0.679 & 0.248 & $0.006^{* *}$ & & -0.565 & 0.177 & $0.001^{* * *}$ \\
\hline BMI & & -0.017 & 0.028 & 0.551 & & 0.077 & 0.026 & $0.004^{* *}$ & & 0.015 & 0.028 & 0.599 & & 0.003 & 0.020 & 0.865 \\
\hline Duration of education ${ }^{2)}$ & & 0.137 & 0.045 & $0.002^{* *}$ & & 0.030 & 0.042 & 0.471 & & 0.119 & 0.045 & $0.009^{* *}$ & & 0.057 & 0.032 & 0.078 \\
\hline Working status ${ }^{3)}$ & & 0.634 & 0.308 & $0.040^{*}$ & & 0.592 & 0.290 & $0.041^{*}$ & & 0.912 & 0.311 & $0.003^{* *}$ & & 0.249 & 0.221 & 0.259 \\
\hline Marital status ${ }^{4}$ & & -0.159 & 0.391 & 0.684 & & -0.580 & 0.368 & 0.116 & & -0.206 & 0.395 & 0.602 & & -0.589 & 0.281 & $0.036^{*}$ \\
\hline
\end{tabular}

1) Gender is defined as male and female.

2) Duration of education are defined as illiterate, literate, primary school, secondary school, high school, university.

3) Working status are defined as working and not working.

${ }^{4)}$ Marital status are defined as single, married and divorced

${ }^{*} P<0.05,{ }^{* *} P<0.001,{ }^{* * *} P<0.0001$

Table 5. Pearson correlation coefficients between EMAQ and PEMS subscales

\begin{tabular}{|c|c|c|c|c|c|c|}
\hline \multicolumn{7}{|c|}{ EMAQ } \\
\hline & Negative emotion & Negative situation & Total negative score & Positive emotion & Positive situation & Total positive score \\
\hline \multicolumn{7}{|l|}{ PEMS } \\
\hline Social & $0.136^{* *}$ & $0.090^{* *}$ & $0.129 * *$ & $0.204^{* *}$ & $0.266^{* *}$ & $0.260^{* *}$ \\
\hline Coping & $0.330^{* *}$ & $0.238^{* *}$ & $0.320^{* *}$ & $0.111^{* *}$ & $0.223^{* *}$ & $0.178^{* *}$ \\
\hline Reward enhancement & $0.228^{* *}$ & $0.163^{* *}$ & $0.221^{* *}$ & $0.212^{* *}$ & $0.275^{* *}$ & $0.270^{* *}$ \\
\hline Conformity & $0.194^{* *}$ & $0.195^{* *}$ & $0.212^{* *}$ & $0.058^{* *}$ & $0.175^{* *}$ & $0.121^{* *}$ \\
\hline
\end{tabular}

** $P<0.001$

\section{$E M A Q$ subscale scores by linear regression analysis}

After modeling performed with age, gender, BMl, duration of education, working status and marital status, which were thought to affect EMAQ subscales, regression analysis was conducted to determine the effect of the stated factors on EMAQ scores. As a result of the analysis, no significant regression results were found between positive emotions, positive situations EMAQ subscales and positive total EMAQ scores and age, gender, BMl, duration of education, working status, and marital status. These subscales were therefore excluded from the table. When regression results on negative subscales were examined, it was seen that a one unit increase in BMI resulted in a 0.293 unit increase in negative situations scores, a 0.626 unit increase in negative emotions scores, and a 0.919 unit increase in negative total EMAQ scores. A one unit increase in education duration resulted in a 0.225 unit increase in negative situations scores, a 0.400 unit increase in negative emotions scores, and a 0.625 unit increase in negative total EMAQ scores. A one unit increase in age resulted in a 0.124 unit decrease in negative emotions scores (Table 3 ).

PEMS subscale scores by linear regression analysis

When the relationship of the same factors with PEMS subscales were examined, it was found that a one unit increase in age resulted in a 0.53 unit decrease in social motives scores, 0.060 unit decrease in coping motives scores, 0.054 in rewards enhancement subscale scores, and 0.029 unit decrease in conformity subscale scores. A one unit increase in BMl increased coping motives scores by 0.077 units. A one unit increase in education duration increased social motives scores by 0.137 units and reward enhancement scores by 0.119 units.

When the significant differences between genders were examined, coping subscale scores of males were found to be 1.187 points higher than females, and conformity subscale scores of males were found to be 0.565 points lower than females. Social, coping, and reward enhancement scores of working people were found to be $0.634,0.525$, and 0.912 points higher than non-working people, respectively (Table 4).

When the relationship between the scales was investigated, it was found that there was a positive correlation among the subscales of both scales $(P<0.05)$ (Table 5$)$.

\section{DISCUSSION}

Today, nutrition is seen by many people as a social activity, sometimes as a method of coping with a negative situation or emotion, and sometimes as a rewarding method. However, this situation may be related to obesity, which is considered as one of the most important health issues.

Although research on emotional eating focused on women, it is apparent that the emotional fluctuations tend to affect individuals' eating behaviors, either causing an increase or a decrease without gender differences and weight [16]. It has been determined that especially when faced with a negative emotion or situation, the feeling of hunger increases and people tend to eat more. In case of a negative situation, men show more eating behavior than women. On the other hand, the level of increased eating behavior for socialization, coping with a negative situation or rewarding was higher in women. eseimilar findings of that the behavior of eating palatable foods for coping with a negative situation was significantly higher in women [17]. In Turkey, there were positive correlations between disorders eating attitudes and depression, obsessive-compulsive symptoms, phobic anxiety in female college students [18]. 
In the United States, mildly obese people had a tendency of eating more when facing a negative emotion, negative situation or both, compared to underweight and normal weight people. On the other hand, it was that underweight and normal weight people had a tendency of eating more when facing a positive situation [19]. In thestudy, the presence of positive emotions or situations did not make a difference in terms of tendency towards eating among BMl groups. However, similar to other studies, it was seen that in the presence of a negative emotion or situation, the tendency of overweight and obese people towards eating was higher than normal or underweight people. In a study on Turkish adolescent individuals, there was positive correlation between BMI and emotional eating [20]. bese people turned towards eating at a rate significantly more than normal weight people. When the findings of both studies are examined, it can be considered that over-eating when experiencing a negative situation or emotion can trigger weight increase in these people. From another point of view, such an eating behavior may be a behavioral pattern that is also related to the body weight of the person. The finding thata one unit increase in $\mathrm{BMI}$ increased the negative scores of EMAQ in the positive direction. It is considered that the educational status was also effective in increasing the negative scores. An increase in education level also increases the tendency to eat when confronted with a negative situation or emotion. The underlying reason can be the improvement in financial situation of people as their education level increases.

On the other hand, when it was investigated whether eating, especially palatable foods, was used as a social tool or as a coping mechanism, it was found that the level of eating for socialization was markedly higher in mildly obese and obese people than in underweight and normal weight people. Eating behavior in order to adapt to an environment or person was also found to be higher in obese people than in underweight people.

Similarly, it was found that those who chose to eat for self-rewarding for any success were usually obese participants, as opposed to underweight and normal weight individuals. The results of a study on university students were also similar. Based on the results of this study, emotional eating were found to be related to BMl and obesity [21]. In another study, it was found that the tendency to consume palatable foods, especially to cope with a negative situation, was found to be much higher in severely obese people $\left(\mathrm{BMl}>40 \mathrm{~kg} / \mathrm{m}^{2}\right)$ [14]. For this reason, whether or not these individuals have such eating behaviors should be taken into account in weight-loss programs applied to these people, and the participants should be surveyed for the presence of frequent eating to cope. When we look at other findings of the current study, an inverse relationship was found between PEMS subscales and age. Along with the decrease in age, there is increase in eating behavior in order to socialize, cope, reward or conform to an environment. The choice of a dining environment and the preference of spending time in such establishments, especially for socializing or conforming to a community at younger ages may be factors that can trigger eating for this purpose at a younger age. In fact, in a study conducted among 12-17 year-old children, it was determined that the BMl of children who developed eating behavior especially for socializing or conforming to an environment were higher than other children [7].

As can be seen from the findings of this study, negative emotional states are highly influential on eating behavior. Therefore, this should not be forgotten by nutritionists, especially today when obesity is emphasized as the disease of the age. Looking at this study, it can be said that eating increases particularly in people who are under the effect of a negative emotion or situation, and there are some limitations of the study in terms of quantitative determination of the effects of this eating behavior on BMI. With further studies to be done, these limitations can be addressed, tests developed to identify the effect of emotional state on eating behavior can be diversified, and these tests can be considered as prospective prediction tools for obesity.

\section{ACKNOWLEDGEMENTS}

We would like to thank all the adults who devoted their time to participate in this study. They are warmly acknowledged for their helpful and wholehearted cooperation.

\section{CONFLICT OF INTEREST}

The authors declare no potential conflicts of interests.

\section{ORCID}

Saniye Bilici: https://orcid.org/0000-0002-1235-0329

Busra Ayhan: https://orcid.org/0000-0001-8617-8552

Efsun Karabudak: https://orcid.org/0000-0002-4210-1657

Eda Koksal: https://orcid.org/0000-0002-7930-9910

\section{REFERENCES}

1. Macht $M$, Simons $G$. Emotions and eating in everyday life. Appetite 2000;35:65-71.

2. Demirel B, Yavuz KF, Karadere ME, Safak Y, Turkcapar MH. The emotional appetite questionnaire (EMAQ)'s reliability and validity and relationship with body mass index and emotional schemas. J Cogn Behav Psychother Res 2014;3:171-81.

3. Bruch H. Eating Disorders: Obesity, Anorexia Nervosa, and the Person Within. New York (NY): Basic Books; 1973. p.35-79.

4. Schachter S, Rodin J. Obese Humans and Rats. Washington, D.C.: Lawrence Erlbaum; 1974. p.24-38.

5. Nolan $\sqcup$, Halperin LB, Geliebter A. Emotional appetite questionnaire. Construct validity and relationship with BMI. Appetite 2010;54: 314-9.

6. Heatherton TF, Baumeister RF. Binge eating as escape from self-awareness. Psychol Bull 1991;110:86-108.

7. Boggiano MM, Wenger LE, Mrug S, Burgess EE, Morgan PR. The kids-Palatable Eating Motives Scale: relation to $\mathrm{BMI}$ and binge eating traits. Eat Behav 2015;17:69-73.

8. Ovaskainen ML, Reinivuo $\mathrm{H}$, Tapanainen $\mathrm{H}$, Hannila ML, Korhonen $\mathrm{T}$, Pakkala $\mathrm{H}$. Snacks as an element of energy intake and food consumption. Eur J Clin Nutr 2006;60:494-501.

9. Bellisle F. Meals and snacking, diet quality and energy balance. Physiol Behav 2014;134:38-43. 
10. Boggiano MM. Palatable Eating Motives Scale in a college population: Distribution of scores and scores associated with greater BMI and binge-eating. Eat Behav 2016;21:95-8.

11. Şanlıer N, Ogretir AD. The relationship between stress and eating behaviors among Turkish adolescence. World Appl Sci J 2008; 4:233-7.

12. Erlanson-Albertsson C. How palatable food disrupts appetite regulation. Basic Clin Pharmacol Toxicol 2005;97:61-73.

13. Bektas M, Bektas I, Selekoğlu Y, Kudubes AA, Altan SS, Ayar D. Psychometric properties of the Turkish version of the Emotional Eating Scale for children and adolescents. Eat Behav 2016;22:217-21.

14. Burgess EE, Turan B, Lokken KL, Morse A, Boggiano MM. Profiling motives behind hedonic eating. Preliminary validation of the Palatable Eating Motives Scale. Appetite 2014;72:66-72.

15. And A, Sylvester MD, Turan B, Uysal Irak D, Ray MK, Boggiano MM. The Turkish Palatable Eating Motives Scale (T-PEMS): utility in predicting binge-eating eating and obesity risk in university students. Eat Weight Disord 2018;23:527-31.
16. Larsen JK, van Strien T, Eisinga R, Engels RC. Gender differences in the association between alexithymia and emotional eating in obese individuals. J Psychosom Res 2006;60:237-43.

17. Boggiano $M M$, Wenger $L E$, Turan $B$, Tatum $M M$, Sylvester MD, Morgan PR, Morse KE, Burgess EE. Real-time sampling of reasons for hedonic food consumption: further validation of the Palatable Eating Motives Scale. Front Psychol 2015;6:744.

18. Celikel FC, Cumurcu BE, Koc M, Etikan I, Yucel B. Psychologic correlates of eating attitudes in Turkish female college students. Compr Psychiatry 2008;49:188-94.

19. van Strien $T$, Herman $C P$, Verheijden MW. Eating style, overeating and weight gain. A prospective 2-year follow-up study in a representative Dutch sample. Appetite 2012;59:782-9.

20. Nogay $\mathrm{NH}$. The role of psychological eating styles in obesity among Turkish adolescents: a cross-sectional study. J Pak Med Assoc 2017;67:573-6.

21. Sevincer GM, Konuk N. Emotional eating. J Mood Disord 2013;3: $171-8$ 